\title{
FIRST WORLDWIDE REGULATION ON SUSTAINABLE LANDFILLING: GUIDELINES OF THE LOMBARDY REGION (ITALY)
}

\author{
Raffaello Cossu 1, Dario Sciunnach 2, Silvia Cappa 2, Giorgio Gallina 2, Valentina Grossule 1,* \\ and Roberto Raga ${ }^{1}$
}

${ }^{1}$ DICEA, Department of Civil, Architectural and Environmental Engineering, University of Padova, via Marzolo 9, 35131 Padova, Italy

${ }^{2}$ Regione Lombardia, Piazza Città di Lombardia 1, 20124 Milano, Italy

Article Info:

Received:

19 August 2020

Accepted:

25 August 2020

Available online:

27 August 2020

Keywords:

Environmental sustainability

Final storage quality

Long term emissions

Final sink

\begin{abstract}
The environmental sustainability principle, since the Rio de Janeiro Conference (1992) and the Kyoto Protocol (1997), has produced a marked change in environmental protection strategies. In waste management practices this trend is reflected in the passage from a linear to a circular approach, where strong attention is paid to the recovery of resources from waste, with a dramatic reduction of untreated waste landfilling. Deposition of waste on soil still plays a crucial role in acting as a final sink for closing materials loop in Circular Economy. Paradoxically the regulations of landfilling at international level appear obsolete, not taking into account the environmental sustainability concept, still promoting unsustainable approaches, with environmental protection measures mainly based on physical barriers, without any consistent control of long term emissions of contaminants which last longer than the barriers themselves. "Guidelines for Sustainable Design and Management of Landfills" issued by the Lombardy Region in 2014 represents the first official regulation which introduced systematically the principle of environmental sustainability. They highlight the modern role of landfilling as a final sink and promote measures and procedures for controlling the mobility of the potential contaminants in the waste, until reaching, within a generation time, a Final Storage Quality in equilibrium with the environment. The aim of this paper is to illustrate and discuss the main aspects introduced by the Guidelines, offering an interesting base for a future spread of the practical application of the sustainability concept to landfilling.
\end{abstract}

\section{INTRODUCTION}

\subsection{Objective of the Guidelines and organisation}

Current legislation on landfilling in Italy (Law $\mathrm{n}^{\circ}$ 36/2003) stems from the European Directive 1999/31/EC. The main drawback of this regulation is that the environmental sustainability concept is not taken into account. This is evident when considering that the main tool to control contaminants emission is the physical barrier (synthetic and mineral liner) which lasts shorter than landfill emissions (Cossu et al., 2020).

As a matter of fact, when considering the origins of the contaminated sites in the Lombardy Region (Italy), a significant number of cases are related to legally authorized landfills, permitted in compliance with the national regulations (Cossu et al, 2017).

Despite the Lombardy Region strongly promoted Circular Economy programmes achieving a dramatic reduction in landfilling (nowadays only $2 \%$ of MSW and $18 \%$ of Industrial waste are landfilled), this system is still necessary.
Considering the potential risk of contamination posed by traditional "legal" landfilling, particularly during the aftercare phase, and recognizing that most of the available areas suitable for landfilling are situated within environmentally sensitive areas, the main goal of the "Guidelines for Sustainable Design and Management of Landfills" issued by the Lombardy Region was to introduce preventive measures by promoting sustainable landfilling. This means adopting any sort of treatment (before or during landfilling) and carrying out management activities that can control long term emissions and achieve environment equilibrium within a generation time (25-30 years).

Additional aims of the Guidelines were the following:

- to introduce homogeneous procedures in the whole Region, combining and integrating different regional regulations and synergizing experiences gained by all the provinces;

to better define a number of features of the national regulations which are not sufficiently clear or detailed 
(e.g. leachate recirculation) or which need to be integrated (e.g. additional physical barriers in sensitive areas).

These Guidelines are the result of two years of collaboration between the Lombardy Region, the University of Padua, the twelve Provinces of Lombardy and ARPA (the Regional Agency for Environmental Protection which carries out on-site inspection in the Lombardy Region).

The Guidelines, written in pursuance of the national law, represents a model adopted by an institutional body for issuing regulations by involving the scientific community and discussing them with all interested stakeholders.

The Guidelines have been developed according to the following steps:

- The first draft was a collection of critical elements deriving from the experiences gained by the institutional bodies (Region, Provinces, ARPAL) in implementing the national regulations;

- The second draft was the result of the collaboration with the University of Padua (18 meetings and workshops between 2012 and 2014);

- The draft text was then presented and discussed at the "Sardinia 2013" Symposium;

- Official presentation and discussion in a public meeting with more than 400 participants, held in Milan, Lombardy Region Congress Hall, on 2nd April 2014

- Open consultation of a collection of written comments by the stakeholders.

- Revision of the text following all the acceptable remarks and transmission of the final version of the Guidelines to the Regional Assembly for final approval.

The Guidelines issued in the form of Regional Law (D.g.r. n. X/2461) were published on 7th October 2014 in the Official Bulletin of the Lombardy Region.

For the first time at an international level, the principle of environmental sustainability was systematically introduced in an official regulation. No legislation worldwide, in fact, to our knowledge, considers the sustainability concept in regulating landfilling (Cossu, 2016; Butti et al., 2019).

The role of landfilling as a final sink for closing the materials cycle has been highlighted and measures and procedures for reducing the mobility of the potential contaminants in the waste have been promoted.

\subsection{Implementation and legal issues}

After the approval, the Guidelines were applied to more than 20 cases, including new landfill sites, the extension of existing ones and the closure of completed landfills with final capping (Cossu et al., 2017).

There have been no problems in applying the technical requirements set by the guidelines, as is the case of the additional confinement barrier, even if this causes a certain loss of storage volume.

The main problem has been that the sustainability principle is still approached more theoretically than practically, without a detailed and consistent planning of all the necessary measures for controlling the long term emissions.
The applicability of the FSQ (Final Storage Quality) value is still uncertain especially when landfilling of special industrial waste is considered.

In December 2015, roughly one year after the approval of the Guidelines, a landfill operator carried out a judicial appeal to the Regional Court of Lombardy Region (TAR-Lombardia) for the cancellation of the guidelines. The Court cancelled the Guidelines (sentence of 17th March 2016, n.522), upholding the action brought by the landfill operator, because only the National Government can legislate on environmental issues, and regional governments cannot make additional laws even if written in accordance with national law. Although the Lombardy Region made an appeal for a revision of the Regional Court decision, in 2017 (9th June, 2017, sentence n. 2790/2017) the final decision of the State Court confirmed the cancellation of the guidelines for the lack of authority of a Regional Government in issuing regulations on Environmental Protection.

Although the compliance is no longer compulsory, the Guidelines, nonetheless, represent a vital technical reference document for landfill designers and public administration officers responsible for permitting.

Excerpts of the Guidelines (highlighted in italics) that concern the most innovative features pertaining to Legislative Decree 36/2003 are reported in the subsequent paragraphs.

\section{PRINCIPLES, SCOPE AND WASTE ACCEP- TANCE CRITERIA}

The Guidelines (GL) of the Lombardy Region on landfills begin by centering on how they fit into the context of regional planning, and on the Circular Economy, "based on integrated management focusing on prevention, preparing for reuse, recycling and recovery. In such a framework, landfill represents the closure of the materials cycle, whereby appropriate techniques and procedures are adopted in order to immobilize elements and substances contained in waste, rendering them harmless and, conversely, to minimise the movement and reactivity of such elements and substances."

\subsection{Principles}

The "Driving Principles" are the cornerstone of the Guidelines. The convergence of politicians, administrators, technicians and citizens on these principles represents an unequivocal basis for the development of regulations directed at promoting environmental sustainability.

Landfills must be designed, built and managed in compliance with the principle of environmental sustainability, by achieving the Final Storage Quality (FSQ) of the landfill (concerning emissions and biological and mechanical stability of waste) in equilibrium with the environment, within a generation time of no more than 30 years from the closure of the landfill or active sectors.

- In order to ensure environmental sustainability, the Final Storage Quality (FSQ) to be achieved during the period of post-operational management, is indicated by the target values (Annex B of the guidelines), which 
project, operational and post-operational management must pursue.

- To attain environmental sustainability, waste to be landfilled should be pre-treated to reduce in advance the mobility of the elements and substances contained therein. In situ treatment or the combination of both in situ- and ex situ-treatment can be alternatively applied to reach the same objective.

- During the planning stage, the methodologies and technologies required to realize environmental sustainability must be justified, described, sized and computed in detail.

- Landfills can be designed to receive homogeneous fractions of waste in order to facilitate possible subsequent landfill mining.

- Landfill must not represent the final use of the site. instead, it should be designed to achieve environmental reclamation with a specific intended use, in compliance with broader local land planning.

- The work on local infrastructure and other work required to achieve the desired use must be specifically planned, and carried out coherently with the various construction stages of the landfill.

- Landfill designs that do not meet environmental sustainability criteria are no longer acceptable.

\subsection{Scope of Application}

The Guidelines have been issued using the same scope of application and in compliance with the national law (Legislative Decree 36/03), establishing the same minimum requirements for planning, authorisation, construction, operational and post-operational management.

\subsection{Waste types and admissibility}

Waste types that are not admitted to landfill (WEEE, packaging, wastes from separate collection, etc.) as well as the conditions and the quantities for the acceptance for other specific wastes, (eg. Waste mixtures) fixed by the guidelines are consistent with Italian and EU regulations as described in Annex A of the guidelines (Admissibility Criteria for Waste in Landfills).

\section{WASTE TREATMENT}

\subsection{Objectives}

"The treatment of waste before landfilling (ex situ) and, if necessary, during landfilling (in situ) should be carried out to reduce the environmental impact in the short and medium-long term, in accordance with the principle of environmental sustainability.

The choice of the type of treatment must be justified and differentiated according to various aspects: goals, process type, technology and level of advancement, references, expected results. Waste treatment can combine ex situ and in situ treatment".

This is a very important point in the Guidelines as the concept of environmental sustainability should be perceived in terms of consistent planning activity, and not simply be interpreted as a couple of fancy words on paper!

\subsection{Ex situ treatments}

The following are examples of ex-situ pre-treatment proposed by the guidelines, depending on the type of waste:

- manual and/or mechanical selection and recovery of fractions with economic value;

- mechanical-biological treatment;

- chemical and/or chemical-physical treatment;

- thermal treatment;

washing;

- specific treatment options as a combination of the above.

\subsection{In situ treatment}

In situ treatment might occur at different stages of landfill life, both during the operational phase and after closure. The following different typologies of in situ treatment are mentioned in the Guidelines:

- aerobic processing of the landfill, by using natural (semi- aerobic) or mechanical (in situ aeration) systems, possibly following a period of anaerobic processing with landfill gas generation;

- natural (open landfills/flushing) or mechanized (water infiltration/leachate recirculation) washing out;

- combined aerobic-anaerobic systems, etc.

These indications are quite important as they reflect the most advanced scientific and technical developments taking place in recent years, which have often been neglected, if not contradicted, by local Authorities.

\section{DESIGNING AND PLANNING}

The Guidelines stipulate that all planning and project actions and the location of the landfill site must comply not only with the provisions of current legislation, but also with the terms already present in the Regional and Provincial Plans of specific reference.

\subsection{Project documentation}

The accompanying documentation to the project (i.e., administrative documents, technical drawings; an environmental compatibility study; technical, hydrogeological/geomorphological reports; operational and post-operational management; surveillance, control and financial plans; a restoration report, as well as environmental and landscape design documents) is listed, with detailed content.

The Technical Report in particular must fulfill the following requirements:

- Describe and design in detail all the planned treatments of waste prior to, during or after the landfill disposal; describe, on the basis of literature, the expected results of the proposed processing;

- Define and estimate the forecast trends of emissions quality over time, focusing on sustainability targets;

- Describe the technical characteristics of the collection and disposal system for wastewater and rainwater, and the discharge point (e.g. sewers, surface water runoff, collection system etc.);

- Assess the mechanical stability of the embankments, 
the working face, the cover and the internal embankments, taking into account a possible earthquake; - Assess the carrying capacity of the bottom of the landfill (including details of the calculation methods) and calculate the forecast subsidence in order to assure the proper functioning of the leachate collection and of the drainage system in maintaining the gradient of the bottom;

- Calculate the total capacity of the landfill, with reference to the forecast degree (\%) of waste compacting and planned use of various sectors;

- Adopted criteria for the allocation in landfill of the received waste;

- Calculate the potential surface runoff and leachate production compared to the time needed to construct the surface cover system, and the size of the leachate collection systems and storage tanks;

- Assess the functioning of the leachate collection wells and of the possible liquid drained between different liners (control methods, measuring and production, pump characteristics);

- Include information on the recirculation and/or other treatment systems in situ and/or ex situ for the treatment of leachate, describing the adopted criteria and proposed targets, and referring to detailed maps and project drawings/charts;

- Include information on systems for monitoring and ensuring the long-term functioning of leachate collection, drainage and storage systems;

In addition, when leachate recirculation is planned it has to be well motivated. The technical aspects have to be appropriately engineered by taking into account the following requirements:

a) Definition of the optimal waste moisture content to be reached and maintained through recirculation. Calculation of the required recirculated volumes and comparison with the estimated leachate volumes being produced and stored;

b) Forecast of the maximum biogas production during recirculation and control of the efficiency of collection, extraction and energy recovery facilities;

c) Assessment and monitoring of the efficiency of the barrier system and of the leachate collection and extraction system in order to ensure the minimum hydraulic head on the bottom, at a level compatible with the pumping and extraction systems;

d) Description of any pre-treatment of leachate deemed necessary to optimise the process;

e) Description of the planned recirculation system (measurement and transfer system from the tanks to the landfill, sizing and positioning of piping system) with detailed descriptive maps/plans

f) Details of the planned additional monitoring required, on top of what has already been authorised, subsequent to the start of recirculation.

The Guidelines enable the use of waste materials for constructing landfills under the following conditions: a) Total quantities for which authorisation is being sought, expressing them both in $\mathrm{m}^{3}$ and the maximum daily total in tons;

b) Results of the tests and analyses proving compliance with the technical and environmental characteristics indicated in Annex D (Use of Waste in Landfill Construction), and a statement of compliance with those conditions;

c) EWC codes, description chemical-physical quality and composition of the waste, its origins and any treatment required to ensure technical suitability for recovery.

Finally, the report on environmental and landscape restoration and adjustment must contain:

a) Overview of the area and surrounding zones regarding the morphology, geomorphology, geology, hydrogeology, climate, soil use, surface hydrogeology, woods, vegetation, management of farming and animals, history and existing facilities;

b) Landscape and environmental quality analysis, maps and, possibly, an analysis of any human settlement and infrastructure;

c) Targets and restrictions on environmental and landscape recovery, considering the timeframe and recovery methods involved;

d) Intended use and final layout of the area, with the study of morphological trends, the layout of the surface area and the relations to the surroundings. Illustration of the work to be done, justification for the chosen solution, resolution of problems tied to the feasibility analysis, including alternatives. In the case of work on a limited area, the report must indicate the architectural details;

e) Planning of the green areas, including indications of trees and bushes to be used and their related agronomic characteristics, as well as broad details about the need for water and maintenance of such plants. The project must illustrate the timing of the interventions in the different phases of the landfill, up to the final restoration.

It is clear that these indications add substance to the principle that the landfill must not in itself constitute a destination of use, but rather represents a viable tool for building and developing destinations of use. In other words, the volume occupied by the waste can represent a precious resource for planning interventions in the area.

Essentially, it is not necessary to design landfills but parks, golf courses, recreation centers, etc., to be built using the waste, and inserting these uses into the territorial planning of a given area.

With these Guidelines "environmental restoration and adjustment" cease to be, in the design documentation, a useless design exercise or an unrealistic pipe dream, but, rather, become an integral part of the whole project.

\section{BASE BARRIER SYSTEM}

The Guidelines shed light on the fact that the base barrier system (lining and drainage) refers to both bottom and side slopes, without any structural differentiation in min- 
eral layers. Specific solutions for the drainage system on side slopes might be accepted in particular cases.

\subsection{Background for the containment system}

The background for the containment barrier - i.e. artificially created low permeability mineral layers should respect the following criteria:

- Control of bearing capability (for the Plate Bearing Test - Swiss Method - the value of the Modulus of Deformation on a $30 \mathrm{~cm}$ plate must be equal to or greater than $50 \mathrm{~N} / \mathrm{mm}^{2}$, calculated with the pressure in the range between 0.15 and $0.25 \mathrm{MPa}$ in the first loading cycle);

- Slopes necessary to guarantee the drainage of the leachate that take into account the expected settlement of the bottom (minimum transversal slope of at least $2 \%$ and a longitudinal slope of at least $1.5 \%$;

- For confined aquifers, the distance between the top of the aquifer and the level of the base barrier, or the formation level for any structure built into the ground to contain leachate must be at least $1.5 \mathrm{~m}$. For unconfined aquifers, this same distance must be $2 \mathrm{~m}$ starting from the maximum level of the aquifer, except for inert landfills where the law sets this distance at $1.5 \mathrm{~m}$ ).

Referring to the last point, having specified the definition of confined aquifer and groundwater, it is still important to foresee the construction of systems (which will remain effective over time) to capture and remove any water that may come into contact with the waste.

The Guidelines also set out criteria for the construction of artificial, not saturated layers and for the evaluation and control of inhomogeneous conditions in the background soil.

\subsection{Barriers}

This is an important and highly sensitive point of the Guidelines which specify the requirements defined by na- tional legislation that have often been the subject of controversy and misinterpretation.

Specifically, where the natural geological barrier established by Legislative Decree no. $36 / 03$ is not existing (e.g. in a permeable area), then an equivalent artificial confinement barrier should be installed. The calculation of the equivalence should refer to the time criterion (based on Darcy's law), which is calculated as the ratio between the thickness of the layer and the permeability of the material that the layer must uniformly be made of.

In addition to the barrier indicated above, for landfills of hazardous and non- hazardous waste, a second and additional confinement barrier is required. According to the above-mentioned criteria the required structures for the different landfill typologies are described in Figure 1.

\section{DRAINAGE AND LEACHATE COLLECTION SYSTEM}

In the structuring of a landfill, the drainage system is one of the most delicate points and yet one of those to which little attention is paid, both at a technical and regulatory level. In addition to recalling the role of the drainage system to "favor the most rapid removal of the leachate", the Guidelines outline the strategic objectives to be observed in its design, namely:

a) to prevent leachate accumulation in the landfill, keeping to a minimum the water head within the waste mass.

b) to reduce the clogging phenomena

c) to allow easy video inspections of the system.

Point a), as observed earlier, has a similar importance to the base barrier: a high leachate head, according to Darcy's law, is equivalent to a higher barrier permeability. Point b) brings into play the quality of the leachate, which depends on the management methods and on the quality
INERT WASTE LANDFILL

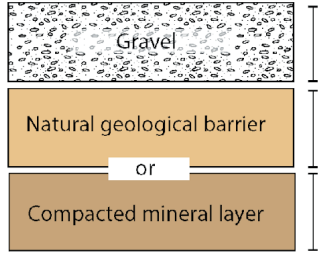

NON-HAZARDOUS WASTE LANDFILL

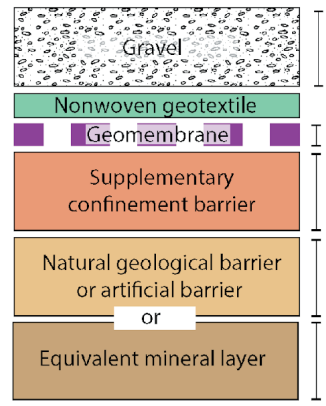

$>0.5 \mathrm{~m}$
$\mathrm{k} \geq 10^{-2} \mathrm{~m} / \mathrm{s}$
$\mathrm{d}=16-64 \mathrm{~mm}$
$>2.5 \mathrm{~mm}, \mathrm{HDPE}$
$>1 \mathrm{~m}$
$\mathrm{k}<10^{-9} \mathrm{~m} / \mathrm{s}$
$>1 \mathrm{~m}$
$\mathrm{k}<10^{-9} \mathrm{~m} / \mathrm{s}$
$>0,5 \mathrm{~m}$
$k$ calculated on the basis
of hydraulic equivalence

HAZARDOUS WASTE LANDFILL

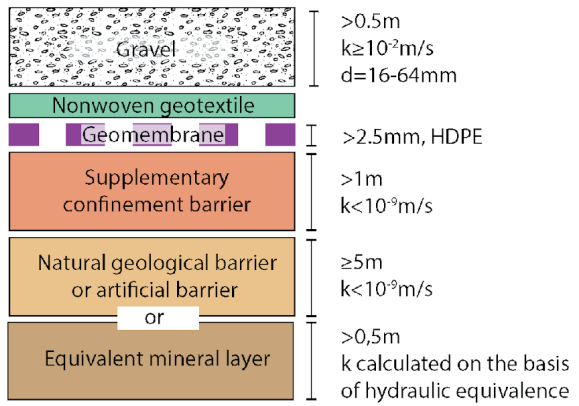

FIGURE 1: Required structures for the different landfill typologies according to the Lombardy region Guidelines. The compacted and equivalent mineral layers have to be artificially made of material from classes A6 and A7 in the HRB AASHTO classification system. The gravel around the drainage piping must be classes $\mathrm{A} 1$ and $\mathrm{A} 3$ of the HRB AASHTO classification system. It should be a washed aggregate with the CE mark (indicatively, gravel with pieces 16- $64 \mathrm{~mm}$ ) with low carbonate content ( $<35 \%$ ), <3\% passing through ASTM 200; with uniform size distribution, a flattening coefficient $<20$ (UNI EN 933-3 standard) and minimum diameter $d>4$ times the size of the openings of the drainage piping; minimum height of $0.5 \mathrm{~m}$ above the crown of the perforated pipe and no less than $2 \mathrm{~m}$ wide at the base. Supplementary confinement barriers have to be made of materials from classes A6 and A7 in the HRB AASHTO classification system; HDPE geomembrane (artificial sealing liner), thickness $\geq 2.5 \mathrm{~mm}$, conforming to the UNI 11309 standard for smooth geomembranes and the UNI 11498 standard for improved geosynthetic barriers; nonwoven geotextiles (minimum resistance to traction in the two longitudinal and transversal directions: 60 kN/m - UNI EN ISO 10319 standard; minimum static puncture resistance: 10 kN - UNI EN ISO 12236 standard; minimum mass per unit area: $1200 \mathrm{~g} / \mathrm{m}^{2}$ - UNI EN 9864 standard) or other suitable protection for the geomembrane. 
of the waste, while point c) points to the need for a design that does not interfere with the inspection (and reparability) of the system through external interventions (video cameras, descaling tools, washing etc.).

In relation to point b), in order to avoid blockages, the Guidelines stipulate that "No synthetic and/or natural materials, acting as filters, should be placed between the drainage system and the waste if their hydraulic conductivity and porosity levels are below that of the drainage layer".

\subsection{Primary and Secondary drainage pipelines}

The Guidelines dictate, for the main perforated drainage pipelines, minimum nominal diameters that are governed not by hydraulic calculations, but by the dimensions of the cameras and inspection and control equipment that may need to be inserted from the outside. As the length to be inspected increases, the overall dimensions of the inspection equipment also increases and consequently the diameter of the pipe must be modified to better adjust to the variation.

The values for the main parameters to be considered when resizing the drainage and collection pipes are given in Table 1.

Further important design measures to be taken are as follows:

- Where the site morphology makes it possible, inspection wells for the drainage pipes must be placed upgradient and downgradient from the collectors and/or outside of the landfill body.

- The secondary drainage pipes must not be connected to the primary collectors so as to not compromise the stability and ability to inspect the latter. Since such piping is not watertight, but offers a preferential drainage route, the pipes do not need to be connected, especially as a connection point might impede inspection or else break due to settling.

- The slope values of the pipelines must refer to the operating conditions,following the complete settlement of the bottom of the landfill.

- The perforations in the pipes must be no smaller than $10 \mathrm{~mm}$ to prevent clogging.

- The drainage piping system must be placed on the geomembrane protection layer and must be tested for mechanical, thermal, chemical and biological stability under the forecast load and operational conditions.

- The bearing capacity of drainage pipes must be determined in a specific calculation taking into account the pressure of the waste column and the pipe covering layer, at the same time taking into account the physical,

TABLE 1: Values of the main parameters for dimensioning primary and secondary pipes in the drainage systems.

\begin{tabular}{c|cccc}
$\begin{array}{c}\text { Drainage } \\
\text { pipes }\end{array}$ & $\begin{array}{c}\text { Minimum } \\
\text { diameter }(\mathbf{m m})\end{array}$ & $\begin{array}{c}\text { Minimum } \\
\text { density }(\mathbf{m} / \mathbf{h a})\end{array}$ & $\begin{array}{c}\text { Pipes distance } \\
(\mathbf{m})\end{array}$ \\
\hline Primary & 315 & 170 & 60 \\
\hline Secondary & 200 & 500 & 20 \\
\hline
\end{tabular}

mechanical and chemical actions.

\subsection{Leachate collection wells}

The Guidelines, in order to avoid any failure or malfunctioning in leachate collection wells, prescribe the following:

- Leachate collection wells must allow easy inspection of the primary leachate drainage collectors.

- Leachate collection wells within the landfill body should be placed preferably on the slopes, with the exclusion of those special cases where there is a need to use vertical wells. For wells located outside the landfill, the isolation system of the well, of the connection to the landfill and of any crossing system of the bottom barrier must meet the equivalent conditions for tightness (sealing) and protection as regards the impermeabilisation system.

- The leachate extraction wells must be designed in order to avoid the potential accumulation of any biogas produced by the landfill.

- The opening size of the leachate collection well must be sufficient to allow inspection and an easy removal of the pumping system for maintenance.

\subsection{Leachate extraction and hydraulic head}

For the functional requirements of the leachate drainage and collection system mentioned above, adequate measures must be taken as follows:

- The system must always be designed so that the pumps start automatically as soon as the lowest technically possible levels of hydraulic head are reached;

- The well must be created so that the bottom is below the level of the drainage network to ensure the proper removal of the leachate;

- The waste mass must have adequate drainage capability or specific facilities should be installed for extracting leachate;

- The waste storage areas must be divided into hydraulically separate basins, with areas of roughly $10,000 \mathrm{~m}^{2}$, measured on the bottom.

- The pumping system must be dimensioned taking into account the surface of the given sector at the start of waste deposing activities; it must ensure the emptying of the sector within 48 hours of the onset of an extreme rainfall event (return period of 10 years and a duration of 48 hours).

\subsection{Leachate Storage}

The leachate storage system must be designed to store the maximum generated amount, calculated by taking into account, as an input datum, the rainfall value in the conditions referred to above - i.e. an extreme rainfall event, lasting 48 hours, with a return period of 10 years. The system must also have a reserve volume of $10 \%$ of the total capacity.

The structure of the storage tanks and the control system should respect the technical requirements set out in a specific national regulation (D.d.g. 07/01/1998 n. 36). 


\section{TOP COVER}

Having reviewed the main functions required of a waste covering system in a landfill (seclusion of waste from the top ambient, control of water infiltration into the waste and control of biogas fugitive emissions), a subdivision of the feasible types of covering is proposed (daily, temporary, permanent), which has multiple design and management implications, to be reviewed later.

\subsection{Daily Covers}

The Guidelines provide specific technical requirements for the materials to be used for daily covers. Specifically, hydraulic permeability should be a constant $k>10^{-3} \mathrm{~m} / \mathrm{s}$. These requirements should also be the technical reference for the acceptability of waste derived materials in daily covering according to the requirements often presented by landfill operators. Additional requirements are the following:

- Quality compatibility with the given landfill type and related admissibility criteria for the permitted waste;

- The amount should be considered within the permitted waste volume;

- Waste delivery should use the permitted disposal methods (D1/D5).

\subsection{Temporary Covers}

Prior to the installation of the final top cover, the Guidelines, in line with the national regulations, allow for a temporary cover for the time required to reach the mechanical and biological stability indicated by the project. Compared to the current legislation which considers only mechanical stability ("settlement"), the Guidelines also include biological stability, on which, in the case of urban waste, the settlements themselves depend. A final cover installed before the waste is reasonably biologically stabilized could slow down its degradation and prolong contaminant emissions over time. From a design point of view, the Guidelines clearly state that the structuring of the surface cover must be compatible with the type of landfill and that, in addition to it being well described and sized in the technical documentation, it "must always, keep the waste separate from the sur- rounding environment (allowing for the movement of gas and/or liquids, as outlined in the project), guarantee proper runoff of surface water and ensure a balanced landscape integration of the landfill, taking into account the duration for which the temporary cover will be in place."

\subsection{Final Capping: General Technical Specification}

For the final covering, the Guidelines refer to the requirements of the national legislation as regards its role and its structure, in accordance with the different types of landfill. The Guidelines then go on to highlight how the multi-layer structure, regardless of the landfill type, must include geotextiles for separating materials with different grain sizes (Figure 2). In order to drain precipitations, the Guidelines prescribe a minimum slope of the top cover, once settling is expired ("less than $3 \%$ for inert landfills and $5 \%$ for other landfill types, in a year").

\section{LEACHATE AND RAINWATER MANAGE- MENT}

\subsection{Rainwater management}

The different types of rainwater that fall on the functional areas of the landfill are considered in the Guidelines (surface cover, roads, parking lots, etc.) which together with the wastewater produced by different services (tyre washing, toilettes, etc.) must be properly managed (drained, collected, treated, recycled, etc.). Here, an important aspect needs to be communicated in big, clear lettering: "Infiltration of precipitation in a landfill might, depending on the waste type, be necessary to improve biological stabilisation and waste leaching." This should be considered as a "leit-motiv" in the design of sustainable landfills, because waste needs water to stabilize and therefore landfills cannot be sealed, thus preventing water from entering the waste body.

\subsection{Leachate Management}

The quantity of leachate foreseen in the various life stages (operational and post-operational) of the landfill must be calculated meticulously by identifying and considering all the parameters that can influence the hydrological balance in the given area and the design solutions

\section{INERT WASTE LANDFILL}

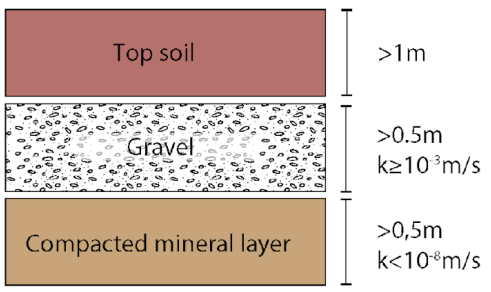

NON-HAZARDOUS WASTE LANDFILL

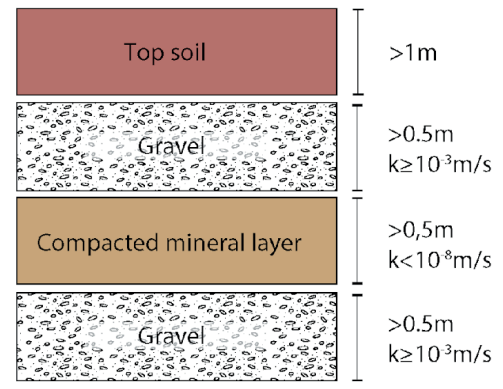

\section{HAZARDOUS WASTE LANDFILL}

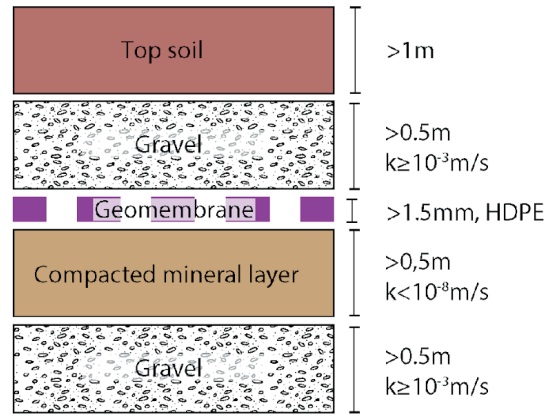

FIGURE 2: Final top cover for Inert, non-hazardous and hazardous waste landfills. The water and gas gravel drainage layer have to be made up by aggregate with the CE Mark, belonging to classes A1 and A3 in the HRB AASHTO classification system; the HDPE geomembrane has to conform to the UNI 11309 standard for smooth geomembranes and the UNI 11498 standard for improved geosynthetic barriers. 
adopted (meteo-climatic characteristics, characteristics of the waste to be deposited, degree of compaction, type of covering, materials used, slopes, surfaces used, storage activities in place, methods for removing surface water, characteristics of a possible greening, etc.).

The Guidelines state that:

- During all stages of the landfill it is important to detect and record the main meteorological-climatic parameters and to verify the estimates of quantity and quality of the leachate produced as the influencing factors vary.

- During the planning stage, final decisions must be made on how the leachate will be managed and how on-site operations will be defined

- The identification of the treatment system must take into account the changes over time in the quality of the leachate, adopting the best techniques available.

- The management of the residues from leachate treatment (sludge, condensates, spent activated carbon, etc.) must be defined. These residues can only be placed in the landfill if they meet the admissibility criteria for waste entering the landfill. This will prevent the accumulation in the landfill of mobile elements and substances that are not degradable, which would otherwise contradict the principle of environmental sustainability.

\subsection{Leachate Recirculation}

This is one of the points that, as already mentioned, has always been the subject of controversy and has resulted in uneven management practices between one Region and another. Undoubtedly, the Guidelines show that recirculation is feasible and permissible only if it is "functional to achieving specific operational targets that have been consistently described in the project" In other words, leachate recirculation must be a technical tool available to the designer to make the landfill more sustainable according to the "Bioreactor landfill" model, and not an expedient to avoid the works necessary for the treatment of the leachate. The Guidelines also contain a series of technical recommendations as follows:

- Recirculation must be compatible with rainfall levels.

- Leachate recirculation must be performed in such a way that uniform distribution can be guaranteed, thus avoiding the formation of aerosols and odours, perched aquifers or preferential infiltration paths.

- The techniques used to distribute the leachate must be defined in the project on the basis of the recirculation targets, taking into account the quality of the leachate and the quantity.

- Leachate recirculation can only commence in the sector of the landfill where waste delivery has been completed. Such recycling is only feasible during the waste delivery stage in specific, suitably justified cases (e.g. to prevent dust spreading)

- Leachate can be recycled untreated or following treatment, depending on the defined targets.

- In traditional anaerobic landfills, recirculation can only commence once the biogas collection system has begun operating.
- Leachate recirculation must be planned and managed so that it does not interfere with gas circulation in the landfill.

- Where a landfill has already been closed, the commencement of leachate recirculation must be carried out so that the cover can be restored without compromising its characteristics.

- Recirculation can only be achieved if the bottom barrier can adequately safeguard the groundwater.

- Leachate injection systems must be placed under the cover to avoid atmospheric emissions, especially bad smells, and to optimise the distribution of leachate in the waste mass.

- The safeguards for the leachate injection system must include a system to monitor and regulate the pressure so that the leachate flows under atmospheric pressure.

- The competent authority can, based on monitoring and specific checks, require that changes be made to recirculation or that additional precautions/measures be adopted.

In addition to the above, the Guidelines set out further requirements to be observed during the operational phase which recognize the importance of:

- Measuring flow rate to determine the volumes of leachate, separating recirculated leachate from disposed leachate;

- Recognizing that only the leachate from the landfill itself can be recirculated;

- Halting recirculation in case of malfunctioning or problems in the bottom barrier system (impermeabilisation and drainage) or in biogas extraction system. The recirculation of the leachate must be halted as a precaution and can only recommence once clearance has been obtained from the competent authority

The Guidelines also provide information about authorization procedures to be adopted in the event that the request for recirculation occurs after the approval and authorization of the landfill.

\section{BIOGAS MANAGEMENT}

As regards the management of landfill gases, the Guidelines clearly specify that the main objective is to minimize the environmental problems that the gas can cause (emissions of greenhouse gases, volatile contaminants or odorous substances). They also suggest that only if there are the right conditions and if economically viable, the gas can be exploited energetically.

Therefore, a very important aspect is sanctioned from the point of view of environmental sustainability, namely that the management of the landfill "must prioritise acceleration in the production of biogas so as to reduce the potential organic matter content of the leachate".

Following conventional indications on the sizing of the biogas management system in line with the landfill cultivation methods, and on structuring the collection and transport network, the Guidelines suggest that the gas not being exploited energetically can be oxidised not only in flares or 
external biofilters but also, when below a production equal to $0.001 \mathrm{Nm}^{3} / \mathrm{m}^{2} / \mathrm{h}$, can be treated in "bio-oxidation covers that must be appropriately sized and designed ". To support this choice, two citations (Rachor et al., 2011; Pedersen et al., 2011) from the literature have been included in the Guidelines referring to experiences where a high oxidation of methane has been achieved with flow rates five times higher than the one indicated above.

\section{USE OF WASTE IN LANDFILL CONSTRUC- TION}

The use of waste materials in landfill construction is one of the most salient points of the Guidelines. In the past, it was left to the scrutiny of the Authoritative Bodies to assess this possibility. Precise indications are given on the possible use of waste materials in the construction of landfills, in terms of admissibility, quality requirements, and consistency of performance over time. These indications are accompanied by detailed technical specifications relating to the different works of the landfill (Annex D - Use of waste for the construction of landfills) and administrative procedures (Annex E).

The main criteria to be observed are the following:

- Waste can be used as the sole material or mixed with other kinds of waste or raw materials. Where mixed waste is used, the environmental protection characteristics and compliance with the definition of "inert waste" must be verified for each type of waste employed, while the geotechnical characteristics must be verified on the mixed material prior to use in the construction of the landfill.

- Settlement forecasting of the material under the predicted loads on the layer must be assessed to guarantee the minimum thickness of the layer and its geotechnical characteristics.

- Permeability must be assessed, under the forecast load after completed closure of the landfill. The geotechnical characteristics must be verified under the most stringent operating conditions.

- The layers must be assessed as part of inspection procedures in compliance with the national regulations.

- The use of waste to form the bottom barrier is not allowed to intrinsically ensure optimal functionality of this key component of a landfill and to be certain of the constant quality of the material used.

- End-of-life tyres can be used as engineering materials.

- The use of inert waste in the construction of landfills is not subject to the specific regulations for inert landfills as already set out in the national regulations "This decree does not apply: (...) to the use of inert waste for development or reconstruction purposes in landfills".

- Recovery activities inherent in waste management must be explicitly authorized in compliance with national regulations.

- The European directive 2008/98/EC classifies the recovery operations into 13 categories from R1 to R13; $\mathrm{R} 5$ represents the recycling/reclamation of inorganic materials, other than metals, including soil cleaning re- sulting in recovery of the soil and recycling of inorganic construction materials. Recovery of waste materials in the construction of landfills must be considered within the framework of R5 mining operations, as it involves the use of waste to replace raw materials (sand and gravel, clay, earth). Considering that the recovered waste is used as a substitute for raw materials, the admissible quantities must be consistent with what is technically necessary for the construction and efficiency of the layer, within the volumes already foreseen by the permitted project.

- The use of such waste is not subject to the payment of the "landfill tax" as it is an R5 recovery operation which is exempt from the application of Legislative Decree $36 / 2003$, unlike the waste used in the layers of landfill cover which is still subject to the "landfill tax".

\section{OTHER DESIGN FEATURES}

Other design features that are considered in the Guidelines are:

- Staff Organisation, with an indication of professional profiles and roles, opening hours of the plants, etc..

- Infrastructure (Entry control systems, Security systems, internal and external access routes with relevant signposting, Weighing point, Wheel cleaning point, Devices (potentially not fixed) to measure radiation levels of incoming waste, Fire-safety systems, Staff block, including change rooms, Vehicle storage area, autonomous generator capable of supporting all landfill users in the event of a power failure of the central electrical unit);

- Monitoring and control of groundwater quality (preliminary investigations for the authorization, organization and structuring of the groundwater control network, construction characteristics of sampling piezometers, frequency of checks, etc.)

- Biogas monitoring network (possible installation of spy wells to control any leakage of biogas outside, groundwater monitoring wells, measures for emergency intervention measures in the electrical substation,);

Compliance verification tests.

\section{CLOSURE PROCEDURES, ENVIRONMEN-} TAL RECOVERY AND RELEASE OF THE FINANCIAL GUARANTEE RELATING TO OPERATIONAL MANAGEMENT

In addition to the procedures for the closure of the landfill (essentially based on the stabilization of settlements), the Guidelines also indicate a list of minimal checks, to positively assess the release of the financial guarantee relating to post-operational management (Article 14, paragraph 3, Legislative decree 36/03).

a) Positive assessment of the environmental recovery work in the area, as per the approved project;

b) Absence of subsidence, fracture or depressions in the cover.

c) Absence of contamination in the groundwater due to the landfill. 
d) Leachate levels in the waste, in the leachate extraction wells and (where applicable) in biogas extraction wells, or in any other wells built no higher than the draft heads of the extraction systems;

e) Properly functioning leachate collection and storage system;

f) Properly functioning biogas extraction and treatment system (where applicable);

g) Properly functioning safeguards (piezometers, fencing, gate, masking);

h) Properly functioning systems/devices (irrigation, fire prevention, road network).

\section{FINAL STORAGE QUALITY (FSQ)}

The most important point of the Guidelines regarding environmental sustainability is the following: "The design and operation of the landfill must be done taking into account the FSQ, as per the expected timetable indicated in the project, which cannot be more than 30 years". Therefore, within the thirty- year timespan, not only financial provisions are forecasted (as set out in the current legislation), but more importantly, the drafting of concrete objectives according to which the designer must guarantee timely and congruous interventions are made clear.

Once the stability of the settlements and the presence of suitable slopes to guarantee the surface runoff of rainwater have been verified, the Guidelines then consolidate the concept of the Final Quality of the Landfill by identifying the target values "which the project, operational management and post-operational management must pursue". These values are shown in a Table inserted in the Guidelines text as Annex B (FSQ target values), reproduced here in full (Table 2).

\section{TECHNICAL AND FINANCIAL REPORTS AND RELATIONSHIPS}

The Guidelines also provide a series of clarifications aimed at resolving some non-univocal interpretations relating to a number of critical aspects of the contents of the Plans according to Legislative Decree 36/03, listed below:

- Operational Management Plan

- Post-Operational Management Plan

- Financial Plan

- Environmental Recovery Plan

- Monitoring and Control Plan

- Annual Report

The Annual Report "must specifically indicate if the planning forecasts for the various parameters leading to the FSQ are accurate or not, and provide details of any corrective measures".

The same report should also contain the following information:

- quantity of leachate recirculated and sent for disposal, compared to the estimated volumes indicated in the permitted technical documentation;
- assessments of the effects of recirculation on the quantities and characteristics of biogas, characteristics of the leachate, settlement of the waste;

- estimated water balance - assessing rainfall infiltration, waste moisture, quantity of leachate produced by the degradation of waste and recirculation, evaporation, leachate sent for disposal - that verifies the absence of significant infiltrations of leachate into the subsoil and the efficacy of the collection and transportation system.

TABLE 2: Target values for the parameters describing the Final Storage Quality (FSQ) in a landfill, Annex B of Lombardy Region Guidelines

\begin{tabular}{|c|c|c|}
\hline Matrix & Parameters & Target values $(\mathrm{mg} / \mathrm{L})$ \\
\hline \multirow[t]{30}{*}{ Leachate } & COD & 1500 \\
\hline & $\mathrm{BOD}_{5} / \mathrm{COD}$ & 0,1 (adim) \\
\hline & Ammoniacal-N & 50 \\
\hline & $\mathrm{Al}$ & 1 \\
\hline & As & 0.5 \\
\hline & $B$ & 2 \\
\hline & $\mathrm{Cd}$ & 0.02 \\
\hline & $\mathrm{Cr}$ & 2 \\
\hline & $\mathrm{Cr}$ VI & 0.2 \\
\hline & $\mathrm{Cu}$ & 1 \\
\hline & $\mathrm{Fe}$ & 2 \\
\hline & $\mathrm{Hg}$ & 0.005 \\
\hline & $\mathrm{Mn}$ & 2 \\
\hline & $\mathrm{Ni}$ & 2 \\
\hline & $\mathrm{Pb}$ & 0.2 \\
\hline & Se & 0.03 \\
\hline & Sn & 10 \\
\hline & $\mathrm{Zn}$ & 3 \\
\hline & $\mathrm{CN}^{-}$ & 0.5 \\
\hline & $\mathrm{SO}_{4}^{-}$ & 1000 \\
\hline & $\mathrm{SO}_{3}$ & 1 \\
\hline & $\mathrm{F}^{-}$ & 6 \\
\hline & Nitric-N & 20 \\
\hline & Total Hydrocarbons & 5 \\
\hline & Phenols & 0.5 \\
\hline & Aromatic organic solvents & 0.2 \\
\hline & $\begin{array}{l}\text { Nitrogenous organic } \\
\text { solvents }\end{array}$ & 0.1 \\
\hline & $\begin{array}{l}\text { Organophosphate pes- } \\
\text { ticides }\end{array}$ & 0.1 \\
\hline & $\begin{array}{l}\text { Total pesticides (exclud- } \\
\text { ing Organophosphate) }\end{array}$ & 0.05 \\
\hline & Chlorinated solvents & 1 \\
\hline Biogas & $\begin{array}{l}\text { Surface emissions with } \\
\text { extraction plant off }\end{array}$ & $0,5 \mathrm{Nl} \mathrm{CH}_{4} /\left(\mathrm{m}^{2} \mathrm{~h}\right)$ \\
\hline \multirow{3}{*}{$\begin{array}{l}\text { Solids } \\
\text { (alternative } \\
\text { methods) }\end{array}$} & $\begin{array}{l}\mathrm{RI}_{4} \text { (Respirometric index } \\
\text { after } 4 \text { days) }\end{array}$ & $2\left(\mathrm{mg} \mathrm{O}_{2} / \mathrm{gST}\right)$ in $4 \mathrm{~d}$ \\
\hline & $\begin{array}{l}\text { IRD (Dynamic Respiro- } \\
\text { metric index) }\end{array}$ & $100 \mathrm{mgO}_{2} / \mathrm{kgSV} / \mathrm{h}$ \\
\hline & $\begin{array}{l}\mathrm{BP}_{21} \text { (Biogas production in } \\
21 \text { days) }\end{array}$ & $5(\mathrm{Nl} / \mathrm{kgST})$ in $21 \mathrm{~d}$ \\
\hline
\end{tabular}




\section{SPECIFIC INDICATIONS FOR MONO-WA- STE LANDFILLS OF CEMENT-ASBESTOS}

Finally, the Lombardy region Guidelines, in compliance with the national regulation (D.M. 27 September, 2010) provide minimal requirements for the construction and operation of landfills for mono-landfilling of asbestos-containing waste. The requirements are to deal with the quality of the acceptable materials, the structure of the barrier systems, biogas and leachate management, gate control and quality inspection, emergency procedures, sampling, depositing procedures, daily, temporary and final cover of the deposited waste, etc.).

\section{CONCLUSIONS}

Whilst all European Union countries are heavily involved in promoting the Circular economy, the "nasty and unsightly landfills" continue to play the fundamental role of closing the materials cycle in waste management. While it is well documented that landfills could be a source of a wide range of environmental problems (e.g., groundwater pollution, odors, greenhouse gases), the national landfill regulations provide technical requirements only for the construction of "traditional" landfill sites, completely overlooking any accomplishments provided by the impressive scientific and technical developments that have taken place in the context of sustainable landfilling in recent years (Cossu, 2016).

Interestingly, in the European Landfill Directive (EU, 1999), which is the mother of all the Member Countries national regulations, the issue of the long term emissions control in the post-operational phase is addressed only in economic terms (art. 8 and art. 10). The Directive sets out for landfill managers a financial provision relating to the covering of after-care costs for a period of at least 30 years. It then decrees, in art. 13 that "...(c) after a landfill has been definitively closed, the operator shall be responsible for its maintenance, monitoring and control in the after-care phase for as long as may be required by the competent authority, taking into account the time during which the landfill could present hazards... (d) for as long as the competent authority considers that a landfill is likely to cause a hazard to the environment and without prejudice to any Community or national legislation as regards liability of the waste holder, the operator of the site shall be responsible for monitoring and analyzing landfill gas and leachate from the site and the groundwater regime in the vicinity..."
As no environmental criteria have been established to determine when "a landfill is likely to cause hazards," the input of data during the planning and design stage relating to how to achieve the aims of Final Storage Quality has not been considered. We all know that the long-term impact of traditional landfilling (the conceptual landfill referred to in the regulation) far exceeds the 30 years covered by the financial provision and, even worse, far exceeds the lifespan of the physical barriers. As a result, the designing of landfills that comply solely with the European Directive might generate contaminated sites, as observed in the Lombardy Region experience.

Despite some controversial legal issues, the history and the technical value of the Lombardy Region Guidelines show that regulations aimed at sustainable landfilling are possible and could be fundamental in turning the general public's negative attitude towards landfilling into a responsible acceptance, considering the unavoidable role of landfilling in any modern waste management strategy.

\section{REFERENCES}

Butti, L., Peres, F., Lops, C., 2019. Legal framework of landfilling in different areas of the world. In Cossu, R., Stegmann, R. Solid Waste Landfilling, Concepts, Processes, Technology. Chapter 1.3, 41-52. Elsevier, 2018, ISBN: 9780128183366.

Cossu R., 2018. Mass balance of contaminants: a key for modern landfill design. In Cossu R., Stegmann R., "Solid Waste Landfilling. Concepts, processes, technologies," Chapter 2.2, 73-88. Elsevier Publisher, ISBN978-0-12-8183366.

Cossu, R., Grossule, V., Lavagnolo, M.C., 2020. La discarica sostenibile: Ruolo nell'Economia Circolare e proposte normative. CISA publisher, ISBN: 9788862650182.

Cossu R., 2016. Back to Earth Sites: From "nasty and unsightly" landfilling to final sink and geological repository.Waste Management, $55,1-2$.

Cossu, R., Landonio, S., Sciunnach, D., Cappa, S., Gallina, G., Raga, R., Rampazzo, R., 2017. The Lombardia Guidelines for design and management of sustainable landfills. In Proceedings: Sardinia 2017. 16th International Waste Management and Landfill Symposium, Santa Margherita di Pula (Cagliari), Italy, 02 - 06 October 2017.

Comitato tecnico discariche (CTD), 1997. Linee guida per le discariche controllate di rifiuti solidi urbani.

EU, 1999. Council Directive 1999/31/EC of 26 April 1999 on the landfill of waste. http://extwprlegs1.fao.org/docs/pdf/eur38106.pdf

Rachor, I., Gebert, J., Gröngröft, A., Pfeiffer, E.M., 2011. Assessment of the methane oxidation capacity of compacted soils intended for use as landfill cover materials. Waste Management, Volume 31, Issue 5, May 2011, Pages 833-842. doi.org/10.1016/j.wasman.2010.10.006.

Pedersen, G.B., Scheutz, C., Kjeldsen, P., 2011. Availability and properties of materials for the Fakse Landfill biocover. Waste Management, Volume 31, Issue 5, May 2011, Pages 884-894. doi. org/10.1016/j.wasman.2010.11.020 